Einen Kühl- und Heizring für Flaschen und Gerätegläser gibt Albert Fräszdorf $f^{1}$ ) an. Diese, namentlich für zylindrische Geräte geeignete Vorrichtung besteht aus einem von einem kalten oder warmen Wasserstrom durchflossenen metallenen Hohlring, welcher auf der Unterseite mit zahlreichen feinen, etwas nach innen gerichteten Löchern versehen ist. In diesen Ring, dessen Öfnung für die vorkommenden Geräte zweckentsprechend ausgewählt ist, stellt man die zu kühlenden oder zu erwärmenden Gefässe, auf deren Oberflüche nun das Wasser in vielen Strahlen gleichmäßig herunterrieselt. Die Zuleitung des Wassers zu dem Ring geschieht auf zweierlei Weise. Entweder ist dieser mit einer Schlauchkuppelung fest verbunden, so dass er direkt an einen beliebigen Wasserhahn angebracht werden kann, oder man versieht ihn mit einem olivenförmigen Ansatz, über welchen ein zur Wasserleitung führender Schlauch gezogen wird. Im letzteren Fall besitzt der Ring weiterhin eine Muffe, mittels deren er an einem der unten beschriebenen Stativstäbe zu befestigen ist. Die betreffenden Geräte stehen auf einem mit Ablauf versehenen Teller, und letzterer kann an zwei durch ein Querstück verbundenen Stäben mittels einer Gleitvorrichtung auf- und abwärts geschoben, also auf jede beliebige, für die verschiedenen Gerätegrössen geeignete Höhe eingestellt werden. Während des Arbeitens hängt man die Vorrichtung mittels des die Stativstäbe verbindenden Querstäcks über den Wasserhahn oder einen Haken, oder stellt sie, was allerdings nur bei dem durch einen Schlauch mit der Wasserleitung verbundenen Modell angängig ist, auf einen Tisch, wie sich dies bei aräometrischen Versuchen empfiehlt. Lässt man das Wasser vor dem Eintreten in den Ring durch eine Kupferschlange gehen, welche in einem Bade erhitzt oder durch Eis gekühlt wird, so kann man jede beliebige, zwischen 0 und $100^{\circ} \mathrm{C}$. liegende Temperatur einstellen. Die Ringe nebst Teller und Halter werden von der Firma Dr. Heinrich Göckel \& Co., Fabrik chemischer Apparate, Berlin NW, Luisenstrasse 21, angefertigt.

Ein neues Laboratoriumswasserbad, beschickt mit destilliertem Wasser, zieht F. Toupla in ${ }^{2}$ ) den mit Leitungswasser gefüllten Bädern vor. Bei letzteren, namentlich bei der Verwendung harten Wassers, bekommen die aufgesetzten Gegenstände, zum Beispiel Platinschalen, einen aus Salzen bestehenden Beschlag, welcher störend sein kann. An Stelle des bekannten Überlaufs für konstantes Niveau besitzt das

1) Chemiker-Zeitung 37, 132.

2) Ann. des Falsifications 5, 307; durch Chem. Zentralblatt 83, II, 658. 
neue Wasserbad einen Kühler, bei welchem man den Durchlauf des Kühlwassers so einstellt, dass das abfliessende Wasser eine Temperatur von etwa $45^{0}$ hat. Die Einrichtung des Wasserbades sowie des Kühlers, welche nichts bemerkenswertes bieten, ergibt sich aus der der Abhandlung beigefügten Figur.

\section{Eine verbesserte Abzugsvorrichtung für den Vakuumexsikkator} nach Haussmann ${ }^{1}$ ) beschreibt F. Dickhäuser ${ }^{2}$ ). Die ursprüngliche Vorrichtung bestand aus einem weiten, oben geschlossenen und mit seitlichem Stutzen versehenen Glasrohr, welches in den Tubus der Exsikkatorglocke eingesetzt wurde. Einerseits sammelt sich nun bei dem Erwärmen eines solchen Exsikkators stets Kondenswasser in dem oberen, kälteren Teil des Aufsatzes an, welches anf die im Exsikkator befindliche Substanz herabtropft, und andererseits kann durch die beim Öffnen des Exsikkators direkt nach unten einströmende Luft leicht ein Teil der Substanz weggeblasen werden. - Der neue Aufsatz besteht ebenfalls aus einem weiten Glasrohr mit seitlichem Stutzen. Der untere Teil ist jedoch etwas ausgezogen and endigt in eine Kugel, auf welcher sich 4 nach oben gerichtete und mit feinen Öffnungen versehene Spitzen befinden. In dieser Glaskugel sammelt sich die abtropfende, kondensierte Flüssigkeit, und durch die Spitzen wird die einströmende Luft geteilt, nach oben, gegen den Exsikkatordeckel, geleitet und der Luftstrom so geschwächt, dass ein Verstäuben auch staubfeiner Substanzen ausgeschlossen ist. Der Apparat wird von der Firma Gebrüder $\mathrm{Mu}$ encke, Berlin $\mathrm{NW}$ 6, Schumannstrasse 2, in den Handel gebracht.

Eine Kristallisierschale, von A. Komaromi ${ }^{3}$ ) beschrieben, ist vornehmlich für fraktionierte Kristallisation bestimmt. Diese Schale besitzt in der Mitte des Bodens eine Öffnung, an welche ein nach unten gehender Tubus augeschmolzen ist. Man verschliesst die Bodenöffnung mit Wasserglas, Kautschuklack, Asphaltlack, Wachs oder Paraffin und giesst die betreffende Lösung in die Schale. Sobald die am schwersten lösliche Verbindung auskristallisiert ist, wird eine andere Schale gleicher Konstruktion unter die erste gestellt und der Verschluss dieser durchstossen. Der Inhalt läuft nun in die zweite Schale, in welcher man die Salze weiter auskristallisieren läsșt. Wie angegeben, verfährt man

\footnotetext{
1) Vergl. diese Zeitschrift 39, 370 (1900).

2) Zeitschrift für angewandte Chemie 25, 529.

3) Pharm. Zentralhalle 53, 1159.
} 